\title{
sciendo
}

\section{What contingency reward indicates - evidence from Bulgaria}

\author{
Miglena PENCHEVA \\ University of Ruse "Angel Kanchev", Ruse, Bulgaria \\ mpencheva@uni-ruse.bg \\ Valentina GHINEA \\ Bucharest University of Economic Studies, Bucharest, Romania \\ valentina_ghinea@yahoo.com
}

\begin{abstract}
Systems diagrams allow one to model the way in which complex systems work. They support thinking through the way in which the factors within a system interact and feedback upon themselves. Leadership, followers' engagement and performance are depicted via Systems diagram approach. Current survey examines leadership behaviour toward followers, i.e. transformational and transactional styles. Full Range Leadership Model is employed to explore leader behavior with respect to Contingency reward. Objective of the paper is to examine Contingency reward within a framework of two surveys. The first one is conducted in 2017 in leading manufacturers in the light industry located in Northeastern Bulgaria. The second study was conducted in 2015 in public administrations located in the North central and Northeastern region in Bulgaria. Respondents in both are first line managers. Average values and validity analysis are performed. As a result, Contingency reward is consistent with transformational leadership.
\end{abstract}

Keywords: Contingency Reward, Full Range Leadership Model, Leadership style, Leadership, System diagram.

\section{Introduction}

Numerous studies have shown the inability of man to penetrate the dynamics of complex systems (Forrester, 1999b; Sterman, 1989), on the one hand - due to the difficulty of deducing the dynamic behavior of accumulation processes, on the other hand - due to non-recognition of causal relationships that are distant in time and space (Moxnes, 2000); mental models - as simple internal images of a supposed functioning of the world, used by each individual in the management of such situations, are therefore most often overwhelmed by their complexity. Equally, however, an extrinsic model can facilitate the understanding of the interaction and interconnectivity between the elements of a system. Thus, a mapping of the dynamic relations that maintain the functioning and functionality of the respective system is performed.

In 2003, in a report on the British economy, Michael Porter was quite cautious in recognizing the importance of management as a decisive factor in national or organizational performance. Looking at things from a macro-economic perspective and based on comparative international economic data, he stressed, on that occasion, the importance of a company's general business environment: infrastructure, economic policies, investment traditions and practices. Managerial capacity, in general, as well as the desire and ability to adopt modern managerial techniques, were more or less seen as a consequence of investing in new technology and a wellprepared workforce, than as a probable cause of increased investment, of keeping up with new technology, strategic positioning and the development of workforce skills (Burgoyne et al., 2004).

However, at present, by reference to daily observations, the dependence of the socioeconomic situation on the efficiency and effectiveness of the activity of organizations, this being, in turn, largely determined by managerial and leadership skills (liable to be learned and / or 
developed), is most likely considered true. In Wren's view, leadership is a reality of any society, essential for the proper functioning of organizations, and not only, regardless of the will and awareness of individuals (Globe, 1999).

Leadership is one of the most commonly discussed areas in management theory and practice. In the last decade, transformational and transactional leadership concepts have been widely employed.

Transformational leadership is defined as leadership of a new type. Unlike traditional leadership models, which describe leadership behavior as a leader-follower relationship, this concept relies on the symbolic behavior of the leader, the use of visionary and inspirational messages, emotional engagement, and etc. The transformation theories aim to study the way a leader influences others. According to House and Podsakoff (1994), transformational (neo charismatic) theories emphasize emotions, preferences, commitment to work by subordinates, and the structure, culture, and performance of organizations. Transformational leadership is a process of influence in which managers change their employees' perceptions of important things and stimulate them to rethink themselves and the opportunities and challenges of the environment in a new way.

Transactional concepts are based on leaders and their interaction with the subordinates. In transactional leadership style, the leader motivates followers by appealing to their self-interest. The leader exchanges money, praise, security, or attention for a well done job, loyalty, or dedication to employees (Bass, 1990). Practically, transactional leaders define and communicate what followers should accomplish, how to accomplish it, and what reward they will receive if they achieve their goals. In case they fail, the transaction leader does corrective action.

The purpose of this study is to outline a specific aspect of the Full Range Leadership Model (FRLM) in Bulgarian environment. The research question in hand is what Contingency reward indicates, is it more influential in Bulgarian environment opposed to more western postulates?

\section{Literature review}

\section{System diagrams}

Originating in the much older path analysis first mentioned by the geneticist Sewall Wright in 1918 (Denis and Legerski, 2006), the analysis of system diagrams (also known as causal loop diagrams), gained in complexity during the 1970s, as a result of the addition of causal loops by Donella Meadows, Dennis Meadows and Jorgen Randers, in order to explain the computer simulation of the World3 model (the developed version of World2, designed by Forrester in 1971); commissioned by the Club of Rome, it aimed at the interaction between population, industrial growth, food production, pollution and the limits of the ecosystem (Turner, 2008).

Later registering a continuous increase in its popularity, it was even more developed towards the end of the last century by Daniel Kim and Peter Senge (Kim, 1993; Senge, 1999).

Fundamentally, the system diagram method is predominantly visual, focusing on the graphical elements that facilitate the understanding of the interdependence between the variables of a system. Thus, the diagrams show a multitude of nodes (symbolizing the variables), as well as a series of arrows representing the relationships between those variables.

In order to build a causal model, it is necessary to set the objective, delimit the system to be analyzed, choose the appropriate temporal step, the necessary degree of detail, as well as identify the state variables that will indicate the situation of that system over time.

Generically, a distinction is made between two types of state variables: conserved state variables (for example, the population of an island or the water behind a dam) and unobserved state 
variables (such as temperature or price), the latter being able to (temperature) or not (price) to record negative values (McGarvey and Hannon, 2004).

Depending on their influence, the relationships between variables can be classified as positive (S-link) or negative (O-link). In the case of a positive causal link (direct, S-type), the variation recorded in both nodes (where the link starts and where it stops) has the same meaning (an increase / decrease of the first will cause an increase / decrease of the other, the reverse not being necessarily true). Conversely, the negative causal link (indirect, type $\mathrm{O}$ ) causes the two nodes to fluctuate in opposite directions (an increase / decrease of the node where the connection starts will cause a decrease / increase of the value of the destination node, again, the reciprocal not necessarily being valid).

\section{Leadership}

As interdisciplinary studies have advanced (the example of socio-economics), new dimensions, such as that of emotional intelligence (known to the general public due to Goleman), have come to complete the old discourses; this trend has been and continues to be sustained by the growing complexity of organizations (Ghinea at al., 2015) that are inducing an increasing interest in explaining the concept of leadership, unlimited to individuals appointed to leadership positions or those classified as "leaders". The need for collaboration, not competition, as well as more frequent contextual changes, imposed a new approach to the concept, thus making the transition from the individualistic model (focused on revealing the set of attributes and defining characteristics of a leader) to the leader's perspective, interdependent with the led group, as a dynamic, shared, relational, global and strategic social complex (Avolio et al., 2009). Despite this new trend, however, management and leadership studies still neglect their own analysis as integrated and complementary processes / activities (Bolden, 2007).

While some authors consider management and leadership to be totally different from the start (for example, in 1993, Boyatzis sees management as concerned with achieving competitive advantage, predictable results and problem solving, and leadership focused on mission, purpose, change, enthusiasm and inspiration), others, on the contrary, tend more towards their inseparability both in life and at work (Burgoyne et al., 2004).

In one way or another, through management or leadership, with or without emotional intelligence, an individual can impose himself and lead groups of people, one or more families, gangs, tribes, states, nations. On an extreme note, it can be said that one can rule oneself, or, just as well, one can rule the whole Earth. However, regardless of the size chosen for the analysis and the mode of action, there are three determining factors that influence each other: the leader (described by certain traits, knowledge and particular skills), the group led (along with its own characteristics), and the environment.

Therefore, whether it is the authority offered by holding an official position within the organization or the ability to inspire confidence and support to achieve the goals set, both manifestations have a considerable impact, whether positive or negative, on beliefs, values, ethics, character, knowledge, skills, etc. of one's own employees or followers.

Looking back, it is found that all societies have created myths. According to Paige, expressed in 1977, the general goal was to explain in a plausible and acceptable way the dominance of leaders, as well as the submission of subordinates (Bass and Bass, 2008). Myths and legends about great leaders have played, and continue to play, an important role in the development of civilized society, most of them having in common a certain heroic behavior (Prometheus brought

fire to the earth, Moses brought the 10 commandments from Mount Sinai, etc.) (Johnson and 
Breckon, 2007). To some extent, history itself proves to be a longitudinal study of leaders (what they did and why), or, in other words, the study of leaders and their leadership, advanced with civilization. And, even if the behavioral patterns considered acceptable or necessary to a leader differed from one period to another, and even from one culture to another, both transversely and longitudinally, there were common points; this supports the universality of the concept. What is equally interesting to note is that the attributes of leadership (power, morality, effectiveness, etc.), have endured over time a process of distortion the more blurred the more troubled the context and socio-economic injustice, higher (Bass and Bass, 2008).

Studies have shown (Smith and Krueger, 1933) that, regardless of geographic area or evolutionary stage, leadership manifests itself equally, even in the absence of formal or official institutions and rules (Lewis, 1974 quoted by Bass and Bass, 2008). Proof of this are concepts and principles regarding leadership attested since the time of the Egyptian hieroglyphs of more than 5000 years ago (leadership - seshemet, leader - seshemu, adept - shemsu), continuing with Greek philosophers such as Plato, Aristotle, etc. (researching the traits necessary for the ideal leader of an ideal state), with Machiavelli who in his work, The Prince (1513), added to the concept characteristics such as perseverance and firmness, authority, power and order in government, and reaching Hegel who proposed, at the beginning of the 19th century, serving from the position of follower before being a leader, for the manifestation of a leadership as effective as possible (Bass and Bass, 2008).

Ignoring the period of their "launch", there is a convergence of leadership theories (meant to define this concept) towards: a) explain the emergence of leaders, b) explain the nature of leadership exercised by different leaders and its manifestation (both considered to be due to the characteristics held, given that the characteristics of the leader determine the typology, and this determines certain particular manifestations), c) but also the explanation of the consequences involved in the various manifestations.

Within the class of explanatory theories of a leader's type and behavior, the theory of the transactional / transformational leader, initially called charismatic (although Bass had highlighted the distinction to be made between the two terms, charisma being only a sub-dimension of transformational leadership, Lievens et al., 1997), has been studied for a long time (Bass, 1997, 1999, 2000; Antonakis et al, 2003; Bono and Judge, 2004; Avolio and Gardner, 2005, etc.); Among the benefits it brings can be listed: increasing the interest of followers, their awareness, facilitating their acceptance of the mission and goals of the group, and their motivation to pursue group interest to the detriment of self-interest (Globe, 1999).

Consider the transformational and transactional leadership through system diagram approach, one could underline that behavioral systems are quite complex and it is challenging to separate unique influence of factors, thus here simplifying is adopted. The scope of the system is limited to the main systems, i.e. leaders/managers, follower/subordinates engagement and individual/organizational performance and their causal linkages depicted on Figure 1. The systems involved are reinforcing loops. They are in a positive casual connection ( $\mathrm{S}$ type). External factors, gaps and delays affecting the system are not taken into account. The focus of the study is limited to the connection between System I and System II. 


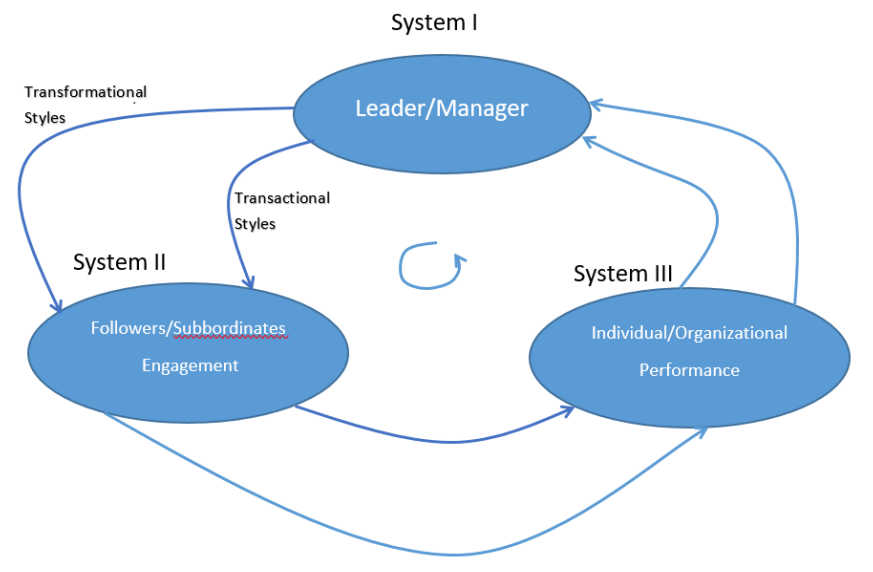

PICBE |

Figure 1. Leader, followers and performance system loop diagram

Source: Authors interpretation.

\section{Transactional and Transformational Leadership}

In 1985, Bernard Bass took over and developed James MacGregor Burs' original 1978 idea of transformational leadership (following the analysis of political leaders, he stated that there is an interaction between leader and follower that can take a transactional or transformational form) ( Bass, 1997). In the early 1990s, the theory of transformational and transactional leadership was placed in a continuum defined by several intermediate stages ("Full range of leadership model" measurable using the MLQ questionnaire, Multilevel Leadership Questionnaire). The novelty of this approach is given by the consideration of the coexistence of the characteristics of both the transformational and transactional leader in the profile of a decision maker, with the specification that, depending on each person, some features are accentuated or faded, taking the transformational or transactional aspect (Bass, 1999; Tejeda et al., 2001).

Based on the results of research conducted so far, four component dimensions have been identified as underlying transformational leadership (Bass, 1997):

- the idealized influence (II) - taking over the precepts of the charismatic leadership theory, reveals the extent to which leaders act as respected, admired human models, able to outline a clear vision, and possessing extraordinary abilities, such as perseverance and determination, high sense of morality and ethics, availability at risk;

- inspirational motivation (IM) - the extent to which, due to enthusiasm, optimism, ability to attribute both meaning and challenge to work, leaders succeed in determining the assimilation of the vision of the organization by their followers, by encouraging team spirit, and creating an atmosphere of attachment to the objectives and vision / mission of the organization;

- intellectual stimulation (IS) - encouraging creativity and fostering an atmosphere free of criticism and conducive to innovation;

- and the consideration given to each individual (IC) - the extent to which leaders act as mentors and instructors, accepting differences and paying attention to the needs of each individual, aided by the skills of active listening, two-way communication and personalized interaction.

Equally, transformational leadership is seen by Bass as wearing two diametrically opposed forms: autocratic and directive leadership, and democratic and participatory leadership (Bass, 1997). 
Sliding to the side of awarding rewards in order to motivate staff to meet organizational objectives, transformational leadership takes the form of transactional, which manifests itself mainly in two directions:

- contingency reward (CR) - leaders clearly express their expectations, negotiate the distribution of resources, basing their activity on mutually beneficial agreements, praising and rewarding successes;

- active leadership in exceptional cases also known as management by exceptions (MBEa) - leaders monitor the performance of subordinates and intervene only when it is necessary to apply corrections to deviate from standards, thus requiring compliance with rules and avoidance of mistakes.

Beyond the transactional dimension of leadership, Bass considers that an inferior form of transactional leadership is positioned, namely the passive leadership with its two characteristics: - passive leadership in exceptional situations also known as management by exceptions (MBEp) non-involvement of leaders until the problems worsen;

- laisser-faire leadership (LF) - avoidance of acceptance of responsibilities and absence in situations that would require the involvement of the leader.

As a result of empirical studies (House and Shamir, 1993 cited by Globe, 1999; Bass, 1997; Bass et al., 2003), it is generally accepted that transformational leadership is more effective than transactional leadership, being much more frequently perceived as ideal leadership. Not only are transformational leaders capable of formulating the most realistic visions, but, regardless of their nature - positive or negative, paying the necessary attention to the specifics of each individual, they succeed and stimulate intellectual subordination, in general, these leaders having the ability to transform both the organization and the individual (Globe, 1999). Ashforth and Humphrey (1995) noted that transformational leadership appears to be dependent on the ability to evoke, frame, and mobilize emotions appropriately, while transactional leadership relies primarily on subordinate knowledge and tendencies, tending to make use of by a rational model of their motivation (extrinsic motivation) (Gardner and Stough, 2002).

At the same time, by maintaining a certain degree of autonomy of subordinates and challenging the tasks assigned to them, transformational leadership can manifest itself as an important factor in achieving job satisfaction (Bass, 1999), an influence passed on to organizational culture.

If when it comes about transactional leadership it is not difficult to intuit that it can be improved through education, training and personal development, taking the result of previous research such as Gibbons in 1986, Avolio and Gibbsons in 1988, but also Bass and Avolio in 1990, Bass brings to the fore the possibility of continuous evolution of the transformational dimension. Thus, the morality transmitted through parental education, school experiences, but also extracurricular ones, are considered to be predictive factors of a transformational tendency, smaller or larger (Popper and Mayseless, 2007; Bass, 1999; Bass and Avolio, 1990).

Correlating Bass's lifelong study with Luthans' (2002) concerns about positive organizational behavior, but also with recent research in positive psychology (Fredrickson, 2001, focusing on analyzing the influence of an individual's positive psychological resources on his or her evolution as a leader), Bass and Steidlmeier (1999) outline the existence of both authentic transformational leaders and mimicked / disguised ones (Avolio et al., 2009).

When it comes to the gap in literature, few areas could be outlined. Contingent Reward is a concept that marks the border between transformational and transactional leadership. "Transactional leadership, particularly contingent reward, provides a broad basis for effective 
leadership, but a greater amount of effort, effectiveness, and satisfaction is possible from transactional leadership if augmented by transformational leadership" (Bass and Riggio, 2006, p. 11). The majority of literature sources allocate $\mathrm{CR}$ in the transactional side of the model.

According to Burgess (2016), another way to envision the Full Range Leadership Model is with performance thresholds: one threshold that leaders must cross to achieve base performance expectations, and another that leaders must cross to achieve extraordinary performance. Leaders build a foundation with transactional leadership and use transformational styles to move their followers across the extraordinary performance threshold where transformation begins (Figure 2).

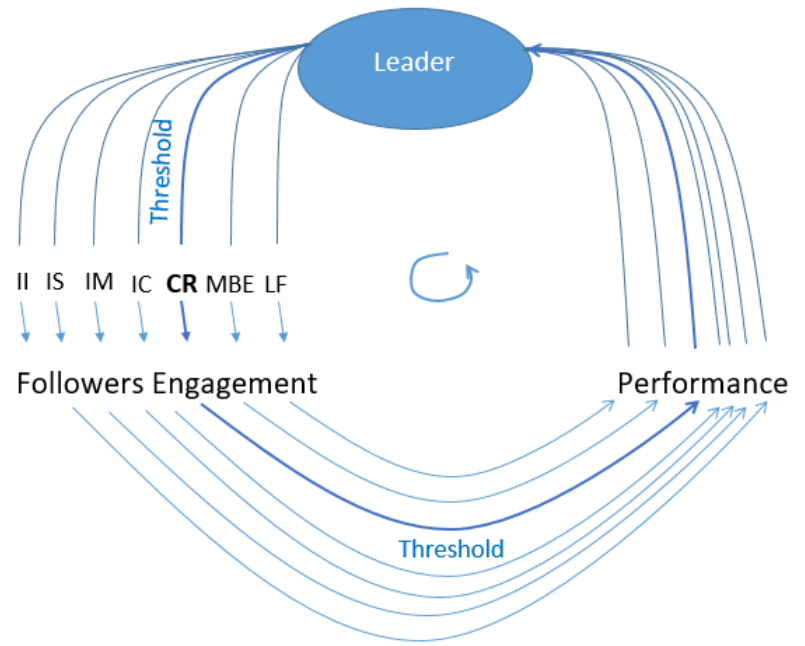

Figure 2. Extraordinary performance threshold

Source: Authors interpretation based on Burges 2016.

Despite the large volume of analysis in the field of transformational and transactional leadership, there are topics with insufficient knowledge or lack of empirical information (Petkova-Gurbalova, 2019). Both transformational and transactional leadership concepts are boldly influenced by the environment, more specifically culturally predisposed. This survey is attempt to outline the Full Range Leadership Model and Contingency reward in particular with Bulgarian traits.

\section{Methodology}

The purpose of this study is to outline specific aspects of the Full Range Leadership Model in Bulgarian environment. The research question in hand is what Contingency reward indicates, is it more influential in Bulgarian environment opposed to more western postulates?

The objective of this study is developed via a qualitative method. Two surveys are employed and compared with respect to Contingency reward scores. The first one was conducted in 2017 in leading manufacturers in light industry, located in Northeastern Bulgaria (Pencheva, 2018). Subjects of study are first line managers $(n=58)$. The second study was conducted in 2015 in public administrations, located in the North central and Northeastern region in Bulgaria (Pencheva, 2016). Subjects of study are people occupying supervisory positions $(n=222)$. Focus in both surveys is a perception of the first line managers towards their leadership behavior in the 
organization they are employed. First line managers are selected for their point of view is more likely to describe the "real picture" opposed to the "ideal one".

\section{Research methods}

Quantitative research methods are employed due to their potential for establishing facts and trends. More specifically, trends based on average values and validity checks. The indicator for the average level is engaged for their ability to generalize quantitative characteristics, which depict typical, representative conditions of the studied trait. Validity is related to the extent to which the scale measures precisely the construct in question. She could be recognized by calculating various coefficients of internal coherence, the most famous of which is the Cronbach's alpha coefficient. The maximum value of $\alpha$ is equal to 1 . Values $\alpha \approx 0.7$ are considered ideal (Pallant 2005). Values of $\alpha \approx 0.6$ show satisfactory reliability (Pallant, 2005). Values below 0.6 are an indicator of unreliability.

With respect to item tool, Multifactor Leadership Questionnaire (5X) is engaged in both surveys to observe the constructs of Full Range Leadership Model. In terms of reliability, the Full range leadership questionnaire has been recognized as a reliable and valid tool (Antonakis et al. 2003). The reliability of the scales varies from 0.74 to 0.94 for each individual substructure (Avolio et al., 1999). Data manipulation is performed with reverse scoring, i.e. $1=$ strongly disagree; $5=$ strongly agree, for consistency with the other construct of the surveys, i.e. organizational culture.

Regarding item validity check, it is possible that a scale has a high internal consistency of the variables as a whole and at the same time, some individual variables could act low in consistency. The main characteristic of a variable is its discriminatory power. The discriminatory power shows the extent to which the variable distinguishes between the high and low results of the studied construct. It is usually measured by the linear correlation coefficient between the score of the relevant variable and the total raw score, without taking into account the contribution of the variable in question. If this coefficient is close to zero, then the variable is random about the scale, and if the coefficient is negative, the variable actually works in the opposite sense. In both cases, elimination of the variable should be considered because it's score does not carry information on the construct under study or destroys the information on the scale. Strong scales are characterized by approximately equal and relatively high values of the coefficients of item discrimination. According to Pallant (2005), if the item correlation coefficient has low values $(<0.3)$, it is likely that the variable in question measures something else. In case Cronbach $\alpha<0.7$ and there is a variable with an item correlation coefficient below 0.3 , the removal of the respective variable should be considered in order to improve the internal consistency of the scale (Pallant, 2005). Practically, the scale can be good even without removing defective variables. An indicator of this is the coefficient $\alpha$ after removal. According to Pallant (2005) if the following two conditions are fulfilled: 1) the total coefficient $\alpha>0.7 ; 2$ ) the scale used is well developed and validated in previous studies; one can make a reasonable decision to keep the variables for subsequent analysis even at values below 0.3 .

The narrowed down research question is how Contingency reward fits $5 \mathrm{X}$ questionnaire scales in the studied samples? Data manipulation is conducted with SPSS (Statistical Package for Social Sciences) software, version 19. 


\section{Results and discussions}

\section{Trend based on average values}

The average values of the leadership items are shown on the tables below. Table 1 depicts average variables value allocated from manufacturing respondents. Table 2 shows results of public administration ones. Both illustrate that the majority of respondents have stated highest importance on Contingency reward no matter the sector they represent. CR actually hits the highest score among all styles in FRLM.

Table 1. Average variable values - manufacturing first line managers

\begin{tabular}{|l|l|}
\hline \multicolumn{1}{|c|}{ Construct } & \multicolumn{1}{c|}{ Mean } \\
\hline CR - Contingency reward & $\mathbf{1 7 , 3 1}$ \\
\hline IC - Individual consideration & 16,67 \\
\hline IM - Inspiring motivation & 16,22 \\
\hline IIb - Idealized influence (behavioral) & 16 \\
\hline IS - Intellectual stimulation & 15,68 \\
\hline IIa - Idealized influence (attributive) & 15,47 \\
\hline MEa - Management by exceptions (active) & 12,67 \\
\hline MEp - Management by exceptions (passive) & 9,12 \\
\hline LF - Laissez - Faire & 6,86 \\
\hline & Source: Pencheva, 2018.
\end{tabular}

Table 2. Construct average values - public administration managers

\begin{tabular}{|l|c|}
\hline \multicolumn{1}{|c|}{ Construct } & Mean \\
\hline \multicolumn{1}{|c|}{ Transformational leadership } & 3,89 \\
\hline IIa - Idealized influence - attributive & 3,72 \\
\hline IIb - Idealized influence - behavioral & 4,05 \\
\hline IM - Inspiring motivation & 3,82 \\
\hline IS - Intellectual stimulation & 3,83 \\
\hline IC - Individual consideration Transactional leadership & 4,01 \\
\hline & \multicolumn{2}{|c|}{2,83} \\
\hline CR - Contingency reward & $\mathbf{4 , 2 1}$ \\
\hline MEa - Management by exceptions - active & 3,13 \\
\hline MEp - Management by exceptions - passive & 2,22 \\
\hline LF - Lasses - faire & 1,78 \\
\hline
\end{tabular}

Source: Authors' own research.

When it comes to highest item (in average) composing Contingency reward in both surveys, it is "helping subordinates if they put an effort". The second item is "provide positive feedback upon meeting expectations".

\section{Scale reliability results}

Cronbach alpha coefficient for Transformational and Transactional leadership is shown on Tables 3 and 4. According to Pallant (2005) values above .7 can be considered reliable with the sample. This is the case with Transformational scale. However, the Transactional one is acceptable with public administration and low with first line managers.

Table 3. Constructs reliability - manufacturing first line managers

\begin{tabular}{|l|l|l|}
\hline & \multicolumn{1}{|c|}{ Items } & \multicolumn{1}{c|}{ Cronbach's Alpha } \\
\hline Transformational leadership & 20 & $\alpha=0,737$ \\
\hline Transactional leadership & 16 & $\alpha=0,497$ \\
\hline
\end{tabular}


Table 4. Constructs reliability - public administration managers

\begin{tabular}{|l|l|l|}
\hline & Items & Cronbach's Alpha \\
\hline Transformational leadership & 20 & $\alpha=0,840$ \\
\hline Transactional leadership & 16 & $\alpha=0,623$ \\
\hline
\end{tabular}

Item analysis is performed to distinguish variables with negative or weak item discriminatory power for both surveys. All the items composing Contingency rewards are

PICBE | 1290 considered as compromised item correlation values. This indicates that the questionnaire does not measure exactly the essence of the construct - Transactional leadership. At the same time, the average values trend distinguishes $\mathrm{CR}$ as the most highly rated. It appears that Contingency reward measures something very strong, and it is not transactional leadership. Based on the high averages of the Contingency reward and the subconstructs of Transformational leadership one could assume that Contingency reward is an element of Transformational leadership for the studied populations. The Cronbach's coefficients have been recalculated along with item analysis for Transformational leadership including Contingency reward. As an outcome: a) Transformational leadership (.840 public administration) + Contingency reward (.694 - public administration) $=0,869$. Thus, Transformational leadership breeds with the inclusion of Contingency reward. Improved internal consistency is obtained from the construct Transformational leadership with the added subconstruct. The Contingency reward item analysis shows values greater than 0.3 for the all four variables, which is an indication that each of these variables is a measure of the nature of the construct and is consistent with the others transformational variables. Thus, it can be deduced that Transformational leadership involves Contingency reward for the studied populations.

\section{Conclusion}

One major outcome of this study is that Contingency reward is consistent with Transformational leadership for the studied populations. Thus, it could be deduced that extraordinary performance threshold moves goes between Contingency reward and Management by exceptions (Figure 3). This gives food for aiming transformational processes with transactional behavior.

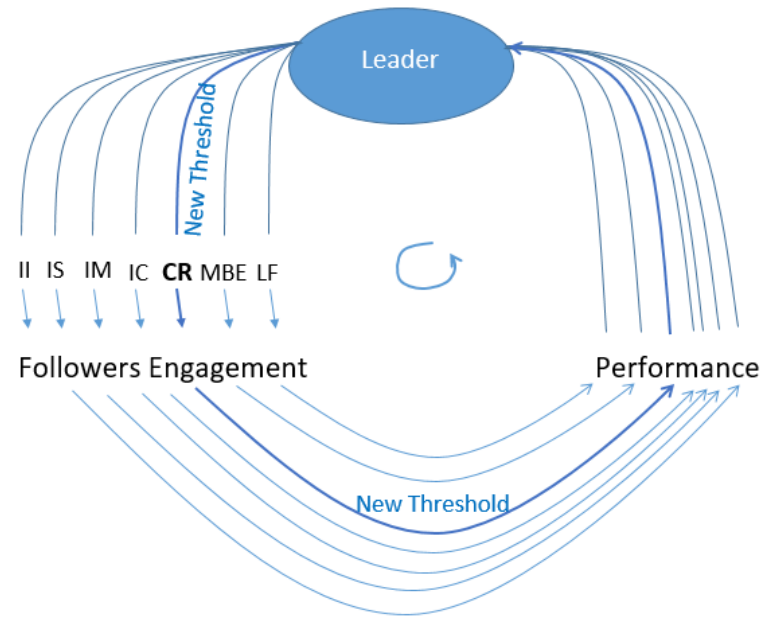

Figure 3. New extraordinary performance threshold

Source: Authors' own research. 
What is more, CR is distinguished as a powerful influencer on followers' engagement. CR is highly recognized for both populations. It questions a bit of a neo-charismatic basis of leadership at the expense of exchange relations instead. The "carrot" comes into focus.

These outcomes should be interpreted with consideration to the following limitations: a) both populations are located in the northern part of Bulgaria. The capital as well as the southern part (with higher economic dynamics) of the country are not represented. b) It is possible to have variation based on generation differences. c) With respect to comparison with other surveys, one should keep in mind the reverse scores indicated in this study.

Burgess (2016) distinguishes CR-I (Intrinsic) and CR-E (Extrinsic). The former is psychological rewards and includes "positive feedback, praise, and approval". The latter is material rewards and includes "a raise in salary, an award, or citation for merit". Exploring this idea of CR division provides ground for further analysis and explorations.

\section{References}

Antonakis, J., Avolio, B.J., Sivasubramaniam, N. (2003). Context and leadership: an examination of the nine-factor full-range leadership theory using the Multifactor Leadership Questionnaire, The Leadership Quarterly, 14, 261-295, Pergamon.

Ashforth, B.E., Humphrey, R.H. (1995). Emotions in the workplace: a reappraisal, Human Relations, 48(2), Sage Social Science Collection.

Avolio, B., Bass, B.M., \& Jung, D.I. (1999). Re-ezamining the componends of transformational and transactional leadership using the multifactor leadership questionnaire, Journal of Occupational and Organizational Psychology, 72, 441-462.

Avolio, B.J., Gardner, W.L. (2005). Authentic leadership development: getting to the root of positive forms of leadership, The Leadership Quarterly, 16, 315-338, Elsevier.

Avolio, B, Walumbwa, F., Weber, T.J. (2009). Leadership: current theories, research, and future directions, Annual Review of Psychology, 60, 421-449.

Bass B.M. (1990). Bass \& Stogdill's handbook of leadership: theory, research, and managerial applications (3rd.ed.), New York, Free Press.

Bass, B.M. (1997). Does the transactional-transformational leadership paradigm transcend organisational and national boundaries?, American Psychologist, 52(2), 130-139, American Psychological Association.

Bass, B.M. (1999). Two decades of research and development in transformational leadership, European Journal of Work and Organisational Psychology, 8(1), 9-32.

Bass, B.M. (2000). The future of leadership in Learning Organizations, The Journal of Leadership Studies, 7(3), Sage Publications, Midwest Academy of Management.

Bass, B.M., Avolio, B.J. (1990). Developing transformational leadership: 1992 and beyond, Journal of European Industrial Training, 14, 21-27.

Bass, B.M., \& Riggio, R.E. (2006). Transformational Leadership (2 ${ }^{\text {nd }}$ Edition), New York, Taylor \& Francis Group, LLC.

Bass, B.M., Steidlmeier, P. (1999). Ethics, character, and authentic transformational leadership behaviour, Leadership Quarterly, 10, 181-217.

Bass, B.M., Avolio, B.J., Jung, D.I., Berson, Y. (2003). Predicting unit performance by assessing transformational and transactional leadership, Journal of Applied Psychology, 88(2), 207-218, American Psychological Association.

Bass, B.M., Bass, R. (2008). The Bass Handbook of leadership. Theory, research \& managerial applications, Free Press (a division of Simon \& Schuster, Inc.), New York. 
Bolden, R. (2007). Trends and Perspectives in Management and Leadership Development, Business Leadership Review, IV:II, Association of MBAs.

Bono, J.E., Judge, T.A. (2004). Personality and transformational leadership: a meta-analysis, Journal of Applied Psychology, 89(5), 901-910, American Psychological Association

Burges, T.P. (2016). Transformational leadership: A great place to begin, Cornwall, NY, Cornwall Leadership Institute disposable at https://cornwallleadershipinstitute.files.wordpress.com/ 2016/10/burgess-tp-2016-transformational-leadership-a-great-place-to-begin1.pdf.

Burgoyne, J., Hirsh, W., Williams, S. (2004). The Development of Management and Leadership Capability and its Contribution to Performance: The evidence, the prospects and the research need, Research Report no. 560, Lancaster University.

Denis, D.J., Legerski, J. (2006). Causal Modeling and the Origins of Path Analysis, Theory \& Science, ISSN 1527-5558 disposable at http://theoryandscience.icaap.org/content/ vol7.1/denis.html.

Forrester, J.W. (1999b). Urban Dynamics, Pegasus Communications, Inc. Waltham.

Fredrickson, B.L. (2001). The role of positive emotions in positive psychology, The Broaden-andBuild theory of positive emotions, American Psychologist, 56(3), 218-226.

Gardner, L., Stough, C. (2002). Examining the relationship between leadership and emotional intelligence in senior level managers, Leadership \& Organizational Development Journal, 23/2, 68-78, Emerald.

Ghinea, V., Mihailova, L., Papazov, E. (2015). Organizational Culture Dynamics. Complex Systems Dynamics.// Quality - access to success, 16(147), 99-105.

GLOBE Research Program (1999). Culture specific and cross-culturally generalizable implicit leadership theories: are attributes of charismatic/transformational leadership universally endorsed?, Leadership Quarterly, 10(2), 219-256, Elsevier Science Inc.

House, R., Podsakoff, P. (1994). "Leadership effectiveness: Past perspectives and future directions for research" in Greenberg, J. (Eds.), Organizational Behavior: The State of the Science. NJ: Hillsdale, 45-82.

Johnson, J.A., Breckon, D.J. (2007). Managing health education and promotion programs, Leadership skills for the $21^{\text {st }}$ century, Jones and Bartlett Publishers, Inc.

Kim, D.H. (1993). A framework and methodology for linking individual and organizational learning: applications in TQM and product development, $\mathrm{PhD}$ thesis submitted in 1986 to the Sloan School of Management, Massachusetts Institute of Technology.

Lievens, F., Van Geit, P., Coetsier, P. (1997). Identification of transformational leadership qualitie: an examination of potential biases, European Journal of Work and Organizational Psychology, 6(4), 415-430, Psychology Press Ltd.

Luthans, F. (2002). The need for and meaning of positive organizational behavior, Journal of Organizational Behavior, 23, 695-706, Wiley InterScience, DOI: 10.1002/job.165.

McGarvey, B., Hannon, B. (2004). Dynamic Modeling for Business Management. An introduction, Springer-Verlag, New-York, Inc.

Moxnes, E. (2000). Not only the tragedy of the commons: misperceptions of feedback and policies for sustainable development, System Dynamics Review, 16(4), 325-348, John Wiley\&Sons, Ltd.

Pallant, J. (2005). SPSS Surviving Manual ( $2^{\text {nd }}$ edn.), Allen \& Unwin. Australia.

Petkova-Gurbalova, I. (2019). Leadership. Contemporary Development Trends: Bulgarian Case, Sofia. 
Pencheva, M. (2016). Leadership and knowledge transfer practices in public administration, Journal of Leadership and Organizational Development, Sofia University St Kliment Ohridski, 358-365.

Pencheva, M. (2018). Leadership Style - Evidence from Manufacturing Industry in Northeastern Bulgaria, Journal of Emerging Trends in Marketing and Management, Bucharest University of Economic Studies, I(1), 192-201, November.

Popper, M., Mayseless, O. (2007). The building blocks of leader development: a psychological conceptual framework, University of Haifa, Department of Psychology.

Senge, P.M. (1999). The fifth discipline. The art and practice of the learning organisation, Random House Business Books, London, Great Britain.

Smith, H.L., Krueger, L.M. (1933). A Brief Summary of Literature on Leadership, Bloomington: Indiana University, School of Education Bulletin.

Sterman, J.D. (1989). Misperceptions of feedback in dynamic decision making, Organizational Behavior and Human Decision Processes, 43.

Tejeda, M.J., Scandura, T.A., Pillai, R. (2001). The MLQ revisited. Psychometric properties and recommendations, The Leadership Quarterly, 12, 31-52, Elsevier.

Turner, G. (2008). A comparison of the Limits to Growth with Thirty Years of Reality, CSIRO working paper series, ISSN 1834-5638. 